\title{
Side lobe reduction in array antenna by using novel design of EBG
}

\author{
M. K. Abdulhameed ${ }^{1}$, M. S. Mohamad Isa ${ }^{2}$, I. M. Ibrahim ${ }^{3}$, Z. Zakaria ${ }^{4}$, Mowafak K. Mohsen ${ }^{5}$, \\ Mothana L. Attiah', Ahmed M. Dinar ${ }^{7}$ \\ ${ }_{1,2,3,4,5,6,7}$ Centre for Telecommunication Research and Innovation (CeTRI), \\ Faculty of Electronic and Computer Engineering, Universiti Teknikal Malaysia Melaka (UTeM), Malaysia \\ ${ }^{1,5}$ Ministry of Higher Education and Scientific Research, University of Kerbala, Iraq
}

\section{Article Info}

Article history:

Received Mar 23, 2019

Revised Aug 18, 2019

Accepted Aug 30, 2019

\section{Keywords:}

Electromagnetic band-gap

Microstrip array antenna

Mushroom-like EBG structure

Side lobe reduction

Triple band gap-EBG

\begin{abstract}
A novel design of EBG is used to replace the mushroom like EBG for surrounding the array patch antenna. In order to improve its radiation performances, Electromagnetic band stop for reducing the surface waves effects is presented. The novel design of Triple Side Slotted EBG (TSSEBG) showed an improvement in the antenna efficiency, directivity and gain as compared to the reference antenna without using EBG, due to reduce the surface waves effects which leads to decrease the side lobes. TSSEBG has been introduced by some modifications in conventional mushroom-like EBG structure. Reducing the complexity was achieved by reducing the number of unit cells and vias, in case of used TSSEBG instead of mushroom like EBG. Additionally, the TSSEBG provided triple band gap compared with mushroom like EBG structure which had only one band gap frequency at $6 \mathrm{GHz}$. The placement of TSSEBG is a flexible structure which provides a good choice in the antenna applications. The simulation results of array patch antenna with and without mushroom like EBG and TSSEBG are arranged in Table 1. This structure has vast applications in satellite communications.
\end{abstract}

Copyright () 2020 Institute of Advanced Engineering and Science. All rights reserved.

\section{Corresponding Author:}

M. K. Abdulhameed,

Department of Telecommunication Engineering, Faculty of Electronic and Computer Engineering,

Universiti Teknikal Malaysia Melaka,

Hang Tuah Jaya, 76100 Durian Tunggal, Melaka.

Email: eng_mka@yahoo.com

\section{INTRODUCTION}

The use of high performance antenna is very important in any wireless system design. Microstrip patch antennas have been applied commonly in numerous purposes due to low profile and cost and appropriate of integration with RF devices [1,2]. In spite of these advantages, the microstrip patch antenna suffers from certain limitations, including low efficiency and low power handling ability due to the surface wave excitations. Surface waves decrease the antenna efficiency, cause a drop in gain, reduce bandwidth, and raise the side lobes and mutual coupling between the radiating elements in the array antenna. In recent years, there has been growing interest in the utilization of the electromagnetic band-gap (EBG) structures. The EBG periodic structure has been applied to microwave planar waveguides can result in pass or stop bands. By accurate choice of dimensions and periods specific waves are permitted for propagatting, whereas the other waves like surface waves can be suppressed. The mushroom like EBG surface has been illustrated in [3] and the other explanation in [4] was the uni planar EBG. The feature of surface-waves suppression supports to reducing backward direction and the amount of power wasted $[5,6]$, leads to improve antenna performance $[7,8]$ by raising the gain of the antenna $[9,10]$ and reduction in antenna size [11]. 
During the last decades, many techniques were developed to reduce surface waves excited by printed antennas. To name only a few: placing an additional dielectric layer over the patch [12], or optimizing the patch shape [13]. Drilling an air cavity below the patch to realize a low effective dielectric constant [14]. The compact circuit design is best achieved on high dielectric constant substrates. As the dielectric constant increases, the surface waves become lower [15], but the side effect for doing this is the band width reduction and this problem can be solved by increasing the substrate thickness [16]. The approach for using EBG is a suitable way to suppress the surface waves which results from the high and thick permittivity substrate due to introduced the stop band around the desired frequency of the antenna. A lower complex and miniature patch antenna can be achieved by surrounding the microstrip patch array antenna by mushroom like EBG, and then replace this EBG by the new design which called Triple side slot EBG (TSSEBG). When considering on inserting additional features to current antennas, the main question is the applications and advantages of doing so.

In this paper, a novel design of EBG, have been introduced from the original mushroom-like EBG structure with compactness feature [17, 18], the EBG structure is called as Triple Side Slotted EBG (TSSEBG). This novel design provides a triple band gap or band stop of frequency below $10 \mathrm{GHz}$ compared with the mushroom EBG structure, which has only one band gap frequency at $6 \mathrm{GHz}$. Array antenna has been surrounded by mushroom like EBG and TSSEBG for reducing the effects of side lobes, backward direction, and the amount of power wasted. All of these lead to improve antenna performance. Due to the connection vias between the patch and the ground plane, mushroom like EBG structure increases manufacturing cost and complexity. By replacing every four cells of the mushroom like EBG by one cell of triple side slotted EBG (TSSEBG), reduction in the number of unit cells and vias have been achieved. The most original contribution of this paper is the reduction of a number of vias, which leads to reduce the number of columns and rows of EBGs in case of used TSSEBG instead of mushroom like EBG.

\section{CONFIGURATIONS OF 2D-EBG}

In this section we designed two types of EBG at the operating frequency of $6 \mathrm{GHz}$, first one is called mushroom like EBG and the other has been introduced from the original mushroom EBG structure, which is called triple side slotted (TSS-EBG).

\subsection{Mushroom like EBG design}

The mushroom like EBG structure consists of four main parts; patch width $(W)$, ground, dielectric constant $\left(\varepsilon_{r}\right)$, the substrate or thickness of the substrate $(h)$, and connecting pin vias. An LC filter model can be applied for the explanation of its operating mechanism. A distinct feature of band gap was exhibited by these EBG structures, were suppressed the surface waves from the propagation. Inductor $(L)$ is due to the current flowing in the pin vias, whereas the effect of the gap $(g)$ between the EBG patches resulted in the capacitor $(C)$. At the resonant frequency of the structure, the impedance is very high, thus the structure prevents the emission of any surface waves [3, 19]. A band gap of the EBG can be generated for frequencies at the same band of the operating frequency, by placing the (EBGs) periodically on the antenna substrate. Antenna structure that results from this design can prevent the excited surface waves along the substrate from the propagation. The transmission line model for plane waves additional to surface waves has been used to cover the frequency of $6 \mathrm{GHz}$. The optimization of the EBG dimensions with all details has been implemented in [20]. Using the microstrip transmission line technique which measuring the surface mutual coupling within two edges as shown in Figure 1(a). The EBG surface mutual coupling, as shown in Figure 1(b), represents the band gap characteristics of the EBG with optimized parameters, where EBG width $W=3 \mathrm{~mm}\left(0.06 \lambda_{\mathrm{o}}\right), g=0.3 \mathrm{~mm}\left(0.006 \lambda_{\mathrm{o}}\right)$, via radius of $0.5 \mathrm{~mm}\left(0.01 \lambda_{\mathrm{o}}\right)$, a Rogers $\mathrm{RT} /$ Duroid 6010 substrate thickness $h=2.74 \mathrm{~mm}\left(0.05 \lambda_{\mathrm{o}}\right)$ and relative permittivity of 10.2. In the case of inserted the pin vias, the EBG structure rejects the surface wave propagation as shown in Figure 1(b).

\subsection{Triple side slotted EBG (TSSEBG) design}

A new shape of $2 \mathrm{D}-\mathrm{EBG}$ is presented and compared with familiar conventional mushroom likeEBG by using transmission line approach. The novel design of Triple Side Slotted EBG (TSSEBG), have been introduced from the original mushroom EBG structure. Complexity reduction has been achieved by reducing the number of unit cells and vias, through replaced every four cells of the conventional mushroom like EBG with one cell of triple side slotted EBG (TSSEBG) as shown in Figure 2(a). TSSEBG consists of a patch and a number of slots, the capacitance is provided by the transverse slot and inductance by different shapes slots [21]. The width of TSSEBG patch $(w)$ is $5 \mathrm{~mm}\left(0.1 \lambda_{o}\right)$, the diameter of via still the same as $1 \mathrm{~mm}$ and three rectangular slots in the right and left sides with the same dimensions $(1.25 \mathrm{~mm} \times 0.3 \mathrm{~mm})$. 
Figure 2(b) shows the 4 elements of conventional mushroom like EBG structure has been modified to introduce the TSSEBG structures. As the mushroom like EBG patch increases, the resonance frequency shifts to the lower frequency side because of an increase in the capacitance value. By inserting the three slots in each of the right and left sides of the new size of EBG will shifting the resonance frequency again to higher frequency, due to a decreases value of capacitance. We know that the inductance formed by pin via was changed, once the number of vias is reduced. So we can change the length of slot to increase the equivalent inductance $\mathrm{L}$, because of increased equivalent length of the current flow path resulting in a lower resonant frequency, and improving the bandgap bandwidth. Additionally, the current has to flow around the slot, and the equivalent length of the current flow path gets longer. Thus, this effect can be described in terms of increase an equivalent inductance [22].

Triple band gap frequency successfully has been achieved in this structure instead of one band gap frequency $(6 \mathrm{GHz})$ for conventional mushroom like EBG structure. Figure 3(a) shows the 3 by 3 TSSEBG structure has been simulated and optimized using the microstrip transmission line technique. The EBG unit cells are sited above the substrate and between the ground plane and microstrip line. The distance between the EBGs and microstrip line is $0.1 \mathrm{~mm}$, the gap between the unit EBG elements $(g)$ is $0.3 \mathrm{~mm}\left(0.006 \lambda_{\mathrm{o}}\right)$. Substrate thickness $h=2.74 \mathrm{~mm}\left(0.05 \lambda_{\mathrm{o}}\right)$ Rogers RT/Duroid 6010, dielectric constant of 10.2 . The width of the transmission line is determined as $2.3 \mathrm{~mm}$, which has been calculated using CST MWS to achieve matching with the $50 \Omega$ input impedance. A couple of $50 \Omega$ discrete ports have been connected at both edges of the transmission line for calculating the EBG band gap characteristics. Figure 3(b) illustrates the rejection of the surface wave propagation according to the forward transmission coefficient $\left(S_{21}\right)$. Based on $-20 \mathrm{~dB} S_{21}$ value, the triple band stop frequencies have been formed. First one has band gap frequency between 4.29 $\mathrm{GHz}$ and 4. $65 \mathrm{GHz}$, the second band is from $5.66 \mathrm{GHz}$ to $6.28 \mathrm{GHz}$, the third band is between $7.6 \mathrm{GHz}$ and $7.94 \mathrm{GHz}$. The simulated value of $S_{11}$ is near to $0 \mathrm{~dB}$ in the range of the band gap frequency indicates that the signal which operates in the same range of band gap frequency cannot propagate on the EBG structure, for more details in [23].

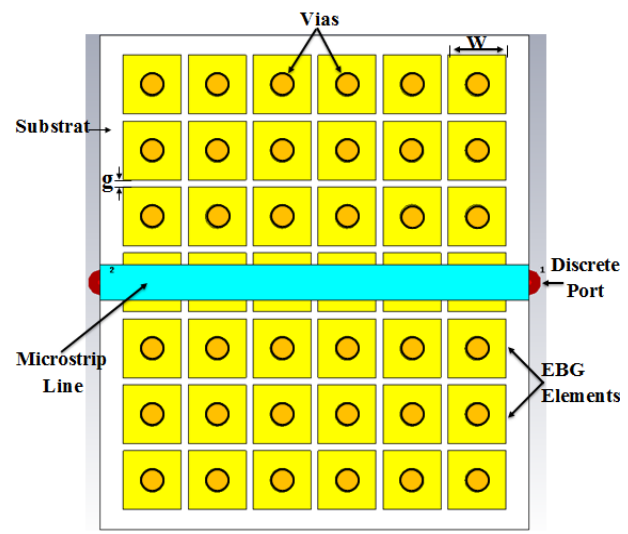

(a)

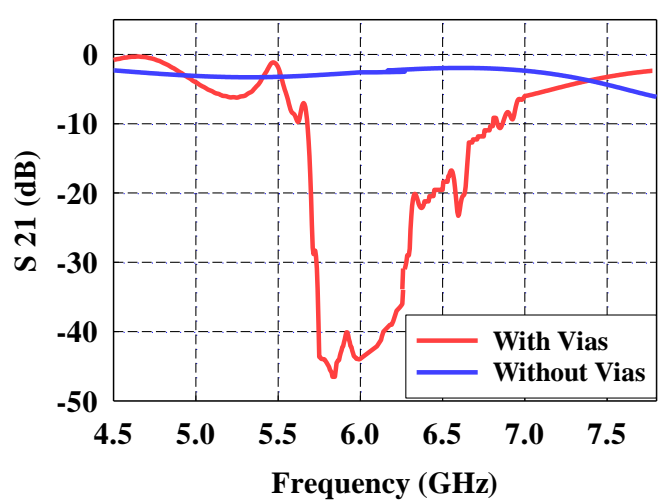

(b)

Figure 1. (a) EBG Microstrip transmission line and, (b) Transmission characteristics of EBG structure

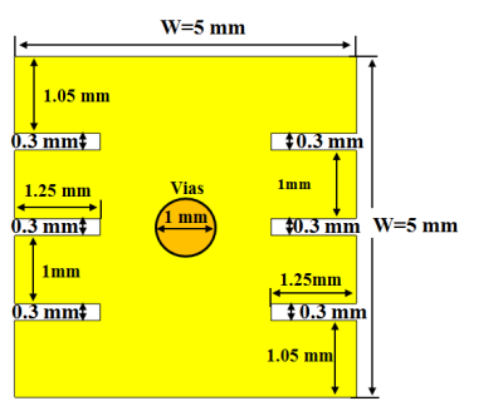

(a)

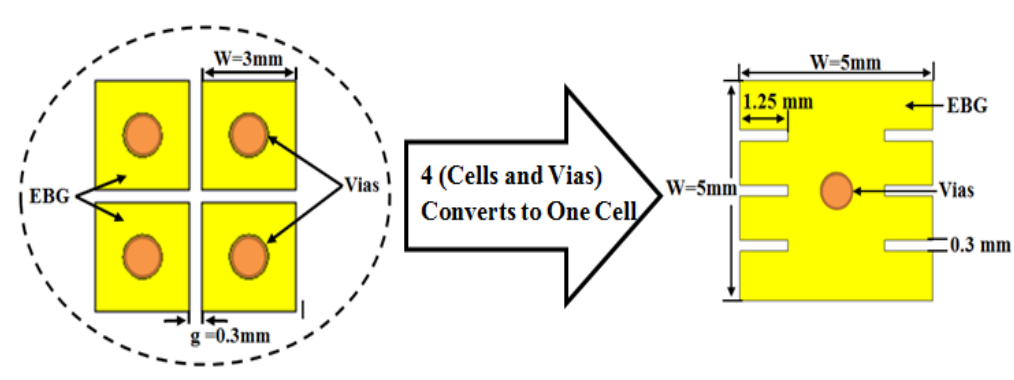

(b)

Figure 2. Triple Side Slotted EBG (a) Unit element,

(b) 4 cells of mushroom likeEBG converts to one cell of TSSEBG 


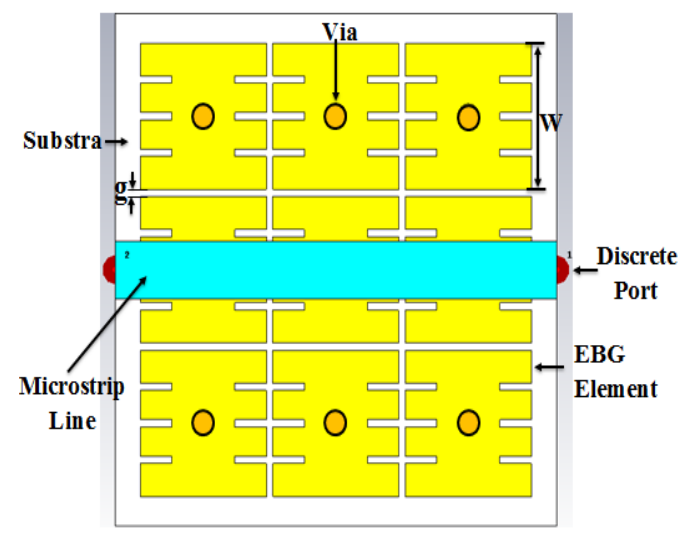

(a)

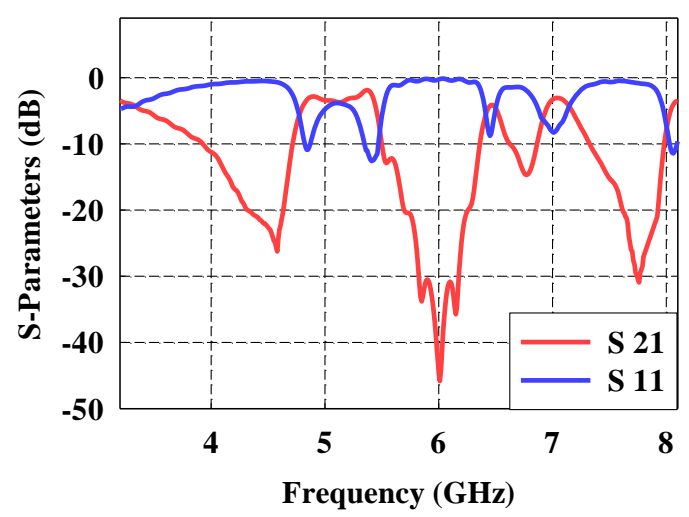

(b)

Figure 3. (a) EBG Microstrip transmission line, (b) Transmission characteristics of TSSEBG structure

\section{ARRAY PATCH ANTENNA WITH MUSHROOM LIKE EBG}

The antenna array design is initiated by choosing the suitable patch antenna shape. This antenna was designed for operating at $6 \mathrm{GHz}$ with $50 \Omega$ input impedance. In this article, a 2x2 rectangular planar array antenna with probe feed on the Rogers RT/Duroid 6010. For avoiding any grating lobe the biggest spacing between the radiating elements should be $<1 \lambda$ [24]. According to the transmission line model, the feedline length is always $\lambda / 4$ [25], in order to attain the best potential impedance matching between the transmission line and the patch elements. The wave attains its impedance inversion at every $\lambda / 4$ distance, and its impedance repeated at every $\lambda / 2$ distance. Dielectric constant $\epsilon_{r}=10.2$, which is the important benefit of utilizing high dielectric constant substrate for reducing the size of the antenna. The antenna on the low $\epsilon_{r}$ substrate has a wider bandwidth than that on high $\epsilon_{r}[17]$.

The bandwidth can be expanded by increasing the thickness of the substrate to $h=2.74 \mathrm{~mm}\left(0.05 \lambda_{\mathrm{o}}\right)$, that will degrade the radiation pattern performance of the antenna and by using EBG we can solve this problem of performance degradation. The lengths of each rectangular patch are $6.8 \mathrm{~mm}\left(0.136 \lambda_{\mathrm{o}}\right)$ by 10.8 $\mathrm{mm}\left(0.216 \lambda_{\mathrm{o}}\right)$ and spacing between the centers of patches to each other $27.1 \mathrm{~mm}\left(0.542 \lambda_{\mathrm{o}}\right)$ where $\lambda_{\mathrm{o}}$ is the free-space wavelength at the resonant frequency $6 \mathrm{GHz}$. The four radiated patch elements have been connected individually by the $70 \Omega$ impedance matching transmission line, and then connected to another transmission line has $50 \Omega$ impedance matching. The insert distance $I d=2.1 \mathrm{~mm}\left(0.042 \lambda_{\mathrm{o}}\right)$ and insert gap $I g=0.7 \mathrm{~mm}\left(0.014 \lambda_{\mathrm{o}}\right)$. These adjustments have been occurred for improving and matching the impedance in order to achieve a better return loss. Mushroom like EBG structures were placed away from the antenna edges by more than three periods, excluding the lower side where EBG structures have been placed more than four periods away from its edges. A pin vias are used for connecting the centers of the EBG square patches to the ground plane as shown in Figure 4(a), stop band of frequency will appear at this connecting process.

In order to compare the array antenna results with and without EBG, the simulations were done to explain the antenna performance. It is observed that when using four columns to surround all sides of array antenna, the simulated S-parameters in terms of $S_{11}$ was established that a good matching (less than $-33 \mathrm{~dB}$ ) at $6 \mathrm{GHz}$, while the $S_{11}$ with less than $-23 \mathrm{~dB}$ was pointed at $6.008 \mathrm{GHz}$ without using EBG as shown in Figure 4(b). The band stop for suppressing surface wave will appear for all antenna borders and no more waves will propagate. The reference array antenna has $-17.9 \mathrm{~dB}$ side lobes, this side lobe will decrease the gain of the antenna. The antenna radiation pattern with EBG detected a better reduction in side lobe -24 $\mathrm{dB}$. These features will generate a better gain and directivity in the direction of the main lobe antenna in comparison to the rectangular planar array antenna without EBG. The measured directivity of the array antenna with EBG is $14.2 \mathrm{dBi}$ and the gain is $13.57 \mathrm{~dB}$, at $0^{\circ}$ main lobe direction, while the directivity and gain of the array antenna without EBG are $11.65 \mathrm{dBi}$ and $10.91 \mathrm{~dB}$ as shown in Figure 5(a) and 5(b) respectively. 


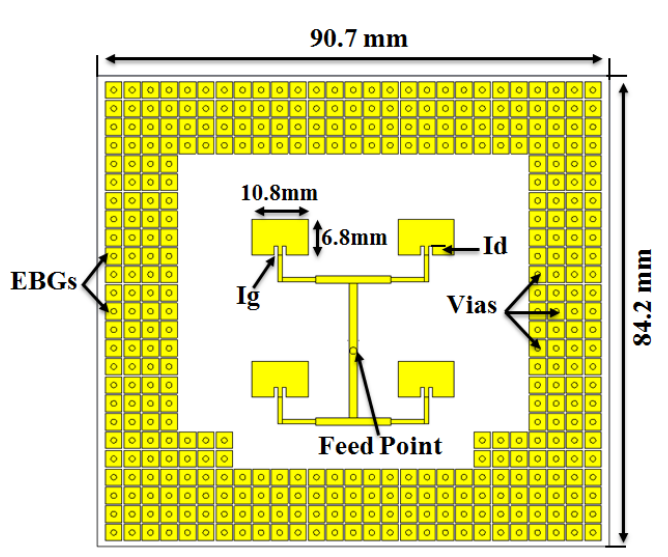

(a)

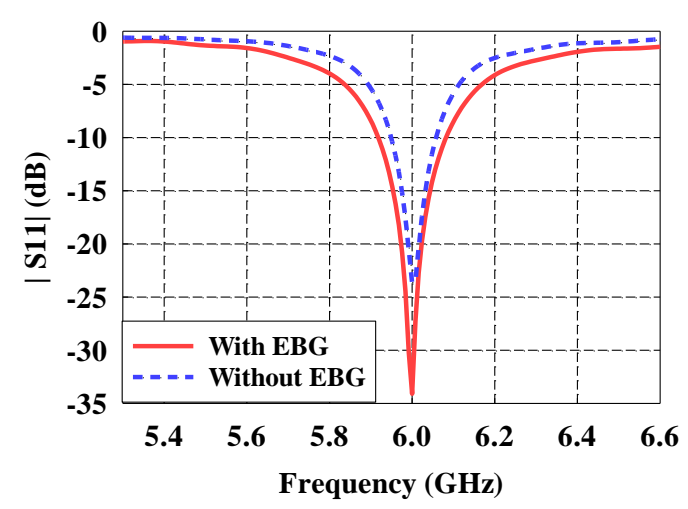

(b)

Figure 4. (a) Array antenna surrounded by EBG structures,

(b) Reflection coefficient of the array antennas with and without EBG

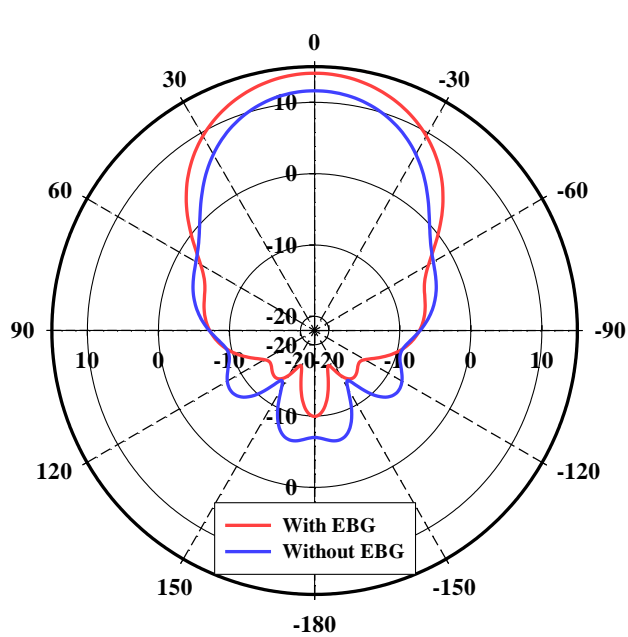

(a)

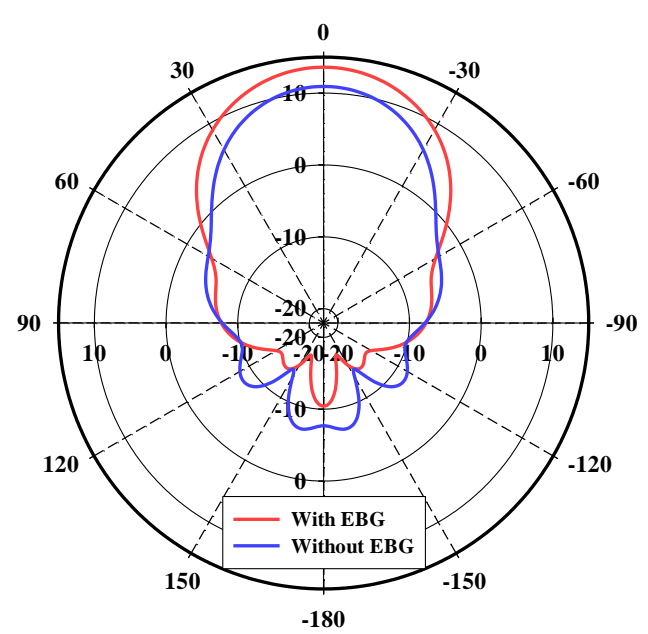

(b)

Figure 5. (a) Directivity improvement of array antenna with and without EBG,

(b) Gain improvement of array antenna with and without EBG

\section{ARRAY PATCH ANTENNA WITH TRIPLE SIDE SLOTTED EBG (TSSEBG)}

As shown in Figure 6(a) the numbers of vias and unit cell have been reduced from (392) to (92), in case of using the TSSEBG instead of mushroom like EBG. The complexity in the design and fabrication has been reduced due to surrounding the same the array antenna in previous design by TSSEBG. Structure of TSSEBGs were located more than one period away from the radiating element edges for all antenna sides except lower side more than two periods of TSSEBG. The gap between the TSSEBG elements $(g)$ is $0.3 \mathrm{~mm}$ $\left(0.006 \lambda_{\mathrm{o}}\right)$. Each of the upper and lower sides is composed of twenty eight square-patches TSSEBG unit cell, and each of the left and right sides is composed of twenty square-patches TSSEBG unit cell or two columns of TSSEBGs for surrounding all antenna sides.

In order to compare the performance for array antenna with and without TSSEBG, simulations were done. It is observed that when using two columns of TSSEBG instead of four columns of mushroom like EBG, the simulated reflection coefficient $\left(S_{11}\right)$ was established that a good matching (less than $-37 \mathrm{~dB}$ ) at $6 \mathrm{GHz}$, while the $S_{11}$ of antenna without using TSSEBG was less than $-23 \mathrm{~dB}$ as shown in Figure $6(\mathrm{~b})$. The radiation pattern properties of the antenna with TSSEBG stated the best reduction in side lobe about $-27.5 \mathrm{~dB}$. These features will generate a better gain and directivity in the direction of the main lobe antenna in comparison to the rectangular planar array antenna without TSSEBG. The measured directivity of the array antenna with TSSEBGs is $15.5 \mathrm{dBi}$ and the gain is $14.3 \mathrm{~dB}$ at $0^{\circ}$ main lobe direction. While the 
directivity and gain of the reference array antenna are $11.65 \mathrm{dBi}$ and $10.91 \mathrm{~dB}$ as shown in Figure 7(a) and Figure 7(b) respectively.

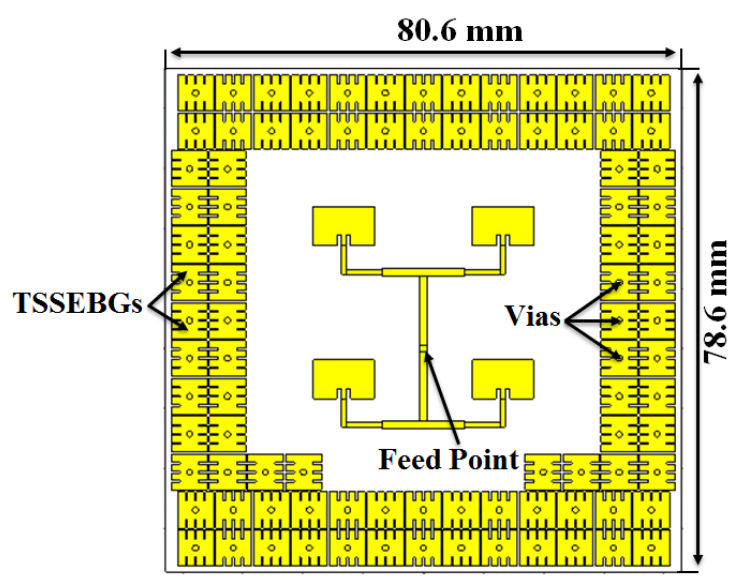

(a)

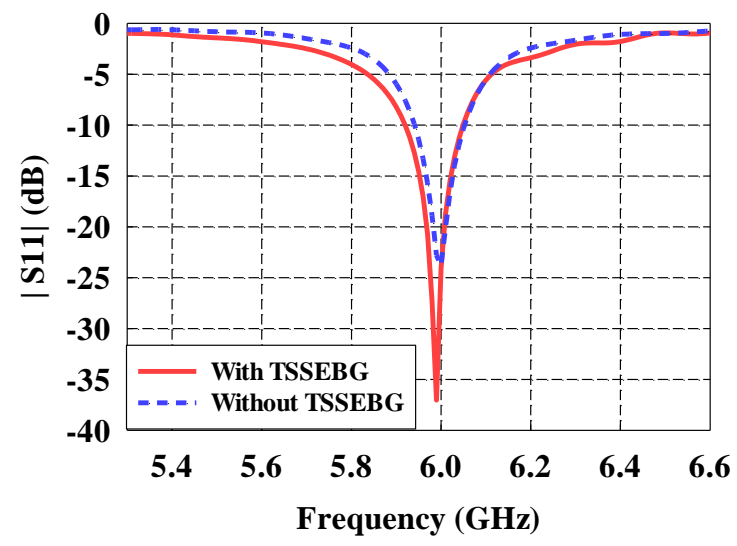

(b)

Figure 6. (a) Array antenna surrounded by TSSEBG structures,

(b) Reflection coefficient of the array antennas with and without TSSEBG

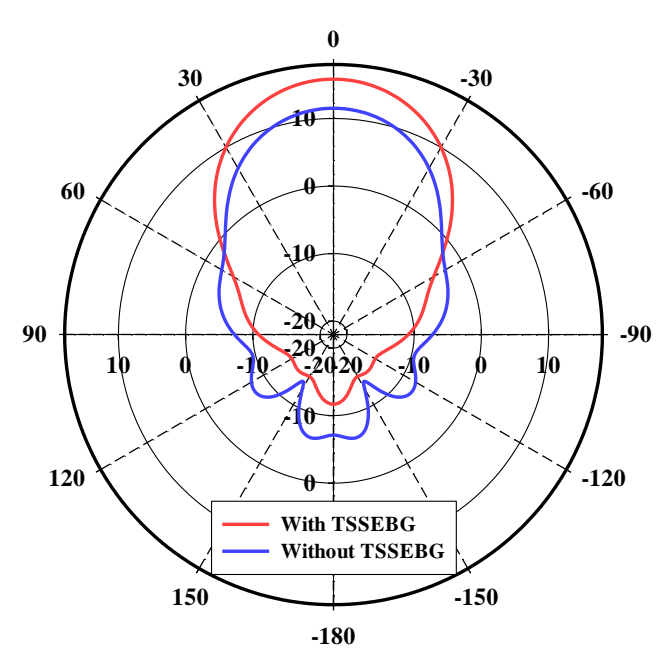

(a)

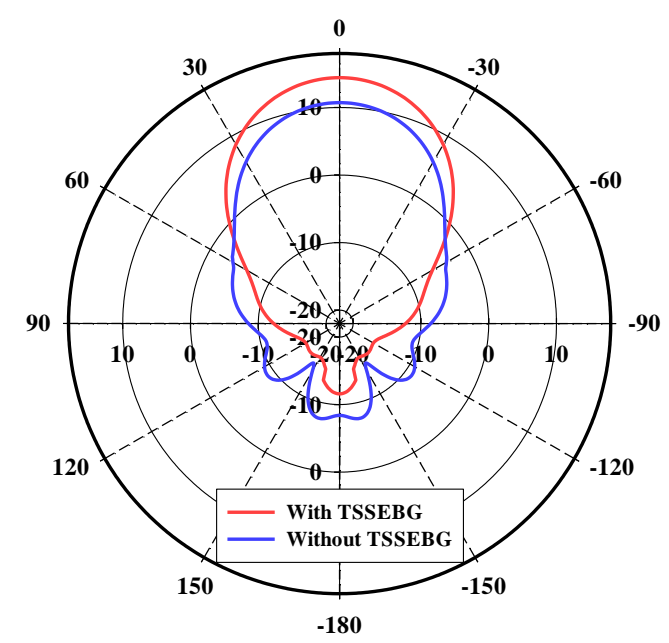

(b)

Figure 7. (a) Directivity of array antenna with and without TSSEBG,

(b) Gain of array antenna with and without TSSEBG

Figure 8(a) presents the radiation patterns of the array antenna without EBG and with EBG and TSSEBG to compare the performance between them. The array antenna without EBG has the lower front radiation; while its back radiation is the largest. The mushroom-like EBG structure has a good radiation performance compared to the array antenna without using EBG. The radiation performance of the TSSEBG structure is the better due to its front radiation pattern is the higher, and it's back radiation is the lower. From this graph, we can conclude that the EBG and TSSEBG have the ability to improve the directivity of the antenna due to the band gap property of EBG. Figure 8(b) shows the improvement of array antenna efficiency. Reference array antenna has an efficiency equal to $84 \%$, and after used the TSSEBG with the same antenna, the efficiency improved to $88 \%$. Achieved the better improvement in $0^{\circ}$ main lobe direction in case of used mushroom like EBG, the efficiency becomes $92.5 \%$. The simulation results without mushroom like EBG and with mushroom like EBG and TSSEBG have been arranged in Table 1 


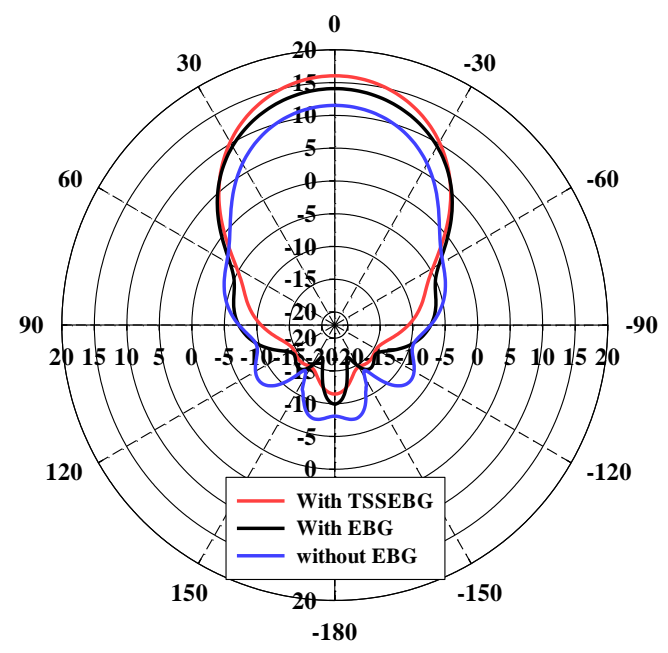

(a)

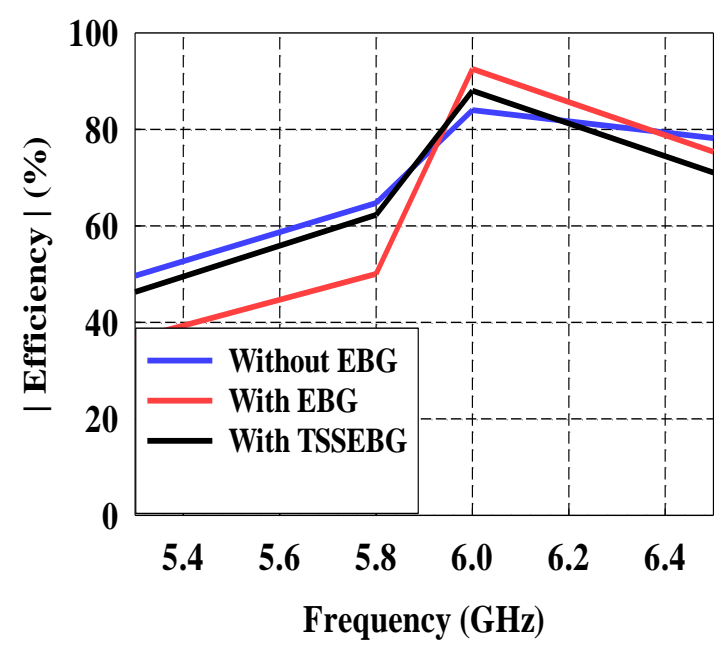

(b)

Figure 8. (a) Improved directivity for array antenna using both of EBG and TSSEBG, (b) Efficiency improvement by using EBG and TSSEBG

Table 1. Summary of antenna's performance without EBG and with EBG and TSSEBG

\begin{tabular}{cccccc}
\hline Antenna Type & Size $(\mathrm{mm})$ & Side lobe $(\mathrm{dB})$ & Gain $(\mathrm{dB})$ & Directivity $(\mathrm{dBi})$ & Efficiency $(\%)$ \\
\hline Array antenna & $81 \times 77$ & -17.9 & 10.91 & 11.65 & 84 \\
Array antenna with EBG & $90 \times 84.2$ & -24 & 13.57 & 14.2 & 92.5 \\
Array antenna with TSSEBG & $80.6 \times 78.6$ & -27.5 & 14.3 & 15.5 & 88 \\
\hline
\end{tabular}

\section{CONCLUSION}

The novel design of EBG has been introduced from the structure of initial mushroom like EBG to surround the microstrip patch array antenna, this design of EBG called as triple side slotted EBG (TSSEBG). Reducing the complexity was achieved by reducing the number of unit cells and vice, in case of use TSSEBG instead of mushroom like EBG. Additionally, the TSSEBG provided triple band gap or stop band of frequencies lower than $10 \mathrm{GHz}$ and compared with mushroom like EBG structure which had only one band gap frequency of $6 \mathrm{GHz}$. The design showed an improvement in the antenna efficiency, directivity, and gain as compared to the reference antenna without using EBG, due to suppress the surface waves which leads to decrease the side and back lobes. The placement of TSSEBG is a flexible structure which provides a good choice in the antenna applications. The design of array patch antenna with mushroom like EBG and TSSEBG represents a good improvement on a high dielectric constant substrate in the antenna performance. These structures have potential applications in satellite communications.

\section{ACKNOWLEDGEMENTS}

This work was supported by UTeM Zamalah Scheme 2019. The authors would also like to thank Center for Research and Innovation Management (CRIM), UTeM's research grant S01529 PJP/2017/FKEKK/HI10/S01529 and Universiti Teknikal Malaysia Melaka (UTeM) for their encouragement and help in sponsoring this study.

\section{REFERENCES}

[1] Tarbouch M., et al., "Realization and Measurements of Compact Dual-band," Int J Electr Comput Eng., vol. 8, pp. $172-8,2018$.

[2] Shah S. M., et al., "Frequency Reconfiguration Mechanism of a PIN Diode on a Reconfigurable Antenna for LTE and WLAN Applications," Int J Electr Comput Eng., vol. 8, pp. 1893-901, 2018.

[3] Sievenpiper D., et al., "High-impedance electromagnetic surfaces with a forbidden frequency band," IEEE Trans Microw Theory Tech., vol. 47, pp. 2059-74, 1999.

[4] Yang F. R., et al., "A uniplanar compact photonic-bandgap (UC-PBG) structure and its applications for microwave circuits," IEEE Trans Microw Theory Tech., vol. 47, pp. 1509-14, 1999. 
[5] Abdulhameed M. K., et al., "Radiation control of microstrip patch antenna by using electromagnetic band gap," International Journal of Electronics and Communications (AE ̈̈), 110 (2019) 152835, pp. 1-11, 2019.

[6] Abdulhameed M. K., et al., "Controlling the Radiation Pattern of Patch Antenna Using Switchable EBG," TELKOMNIKA (Telecommunication Comput Electron Control), vol. 16, pp. 2014-22, 2018.

[7] Gonzalo R., et al., "Enhanced patch-antenna performance by suppressing surface waves using photonic-bandgap substrates," IEEE Trans Microw Theory Tech., vol. 47, pp. 2131-8, 1999.

[8] Neo C. and Lee Y. H., "Patch antenna enhancement using a mushroom-like EBG structures," IEEE Antennas Propag Soc AP-S Int Symp, vol. 1, pp. 614-5, 2013.

[9] Ebg W. and Reflector V., "Gain Improvement of MSAs Array by V sing Curved," Int Electr Eng Congr IEEE, pp. 4-7, 2014.

[10] Abdulhameed M. K., et al., "Mushroom-Like EBG to Improve Patch Antenna Performance For C-Band Satellite Application," Int J Electr Comput Eng., vol. 8, 2018.

[11] Zaid J., et al., "Miniaturized Microstrip Patch Antenna Using Electromagnetic Band Gap (EBG) structures for Multiport Passive UHF RFID-Tag Applications," IEEE, pp. 2459-60, 2017.

[12] Alexópoulos N. G. and Jackson D. R., "Fundamental Superstrate (Cover) Effects on Printed Circuit Antennas," IEEE Trans Antennas Propag, vol. 32, pp. 807-16, 1984.

[13] Jackson D. R., et al., "Microstrip Patch Designs That Do Not Excite Surface Waves," IEEE Trans Antennas Propag, vol. 41, pp. 1026-37, 1993.

[14] Yook J. G. and Katehi L. P. B., "Micromachined microstrip patch antenna with controlled mutual coupling and surface waves," IEEE Trans Antennas Propag., vol. 49, pp. 1282-9, 2001.

[15] Weile D. S., "Electromagnetic Band Gap Structures in Antenna Engineering [Reviews and abstracts]," IEEE Antennas Propag Mag., vol. 55, pp. 152-3, 2013.

[16] Rong H. and Wang Q., "Wide stopband miniaturized "I" -typed EBG with DGS," Microw Opt Technol Lett., vol. 60, pp. 44-50, 2017

[17] Yang F., et al., "Step-like structure and EBG structure to improve the performance of patch antennas on high dielectric substrate," IEEE Antennas Propag Soc Int Symp 2001 Dig Held conjunction with Usn Natl Radio Sci Meet (Cat No01CH37229), vol. 2, pp. 482-5, 2001.

[18] Abdulhameed M. K., et al., "Improvement of Microstrip Antenna Performance on Thick and High Permittivity Substrate with Electromagnetic Band Gap,” Jour Adv Res Dyn Control Syst., vol. 10, pp. 661-9, 2018.

[19] Abdulhameed M. K., et al., "Review of Radiation Pattern Control Characteristics for The Microstrip Antenna Based On Electromagnetic Band Gap (EB),"J Telecommun Electron Comput Eng., vol. 10, pp. 129-40, 2018.

[20] Abdulhameed M. K., et al., "Radiation Pattern Control of Microstrip Antenna in Elevation and Azimuth Planes Using EBG and Pin Diode," Int J Electr Comput Eng., vol. 9, 2019.

[21] Iskander D. N. E., et al., "Microstrip array antenna with new 2D-Electromagnetic band gap structure shapes to reduce harmonics and mutual coupling," Prog Electromagn Res C., vol. 12, pp. 203-13, 2010.

[22] Zhang X. and Yang F., "Study of a slit cut on a microstrip antenna and its applications," Microw Opt Technol Lett., vol. 18, pp. 297-300, 1998.

[23] Abdulhameed M. K., et al., "Novel design of triple-band EBG," TELKOMNIKA Telecommunication Computing, Electronics and Control, vol. 17, pp. 1683-1691, 2019.

[24] Bhuvaneswari B., et al., "Effect of placing mushroom electromagnetic bandgap structures at the inset feedline of microstrip patches," IET Microwaves, Antennas Propag., vol. 6, pp. 1487-97, 2012.

[25] Balanis C. A., “Antenna Theory: Analysis and Design," Electronics and Power, vol. 28, pp. 1136, 2012. 